\title{
Sex in murky waters: algal-induced turbidity increases sexual selection in pipefish
}

\author{
Josefin Sundin $^{1,2}$ (I) Tonje Aronsen ${ }^{3,4} \cdot$ Gunilla Rosenqvist $^{3} \cdot$ Anders Berglund $^{1}$
}

Received: 7 November 2016 / Revised: 23 March 2017 / Accepted: 28 March 2017 /Published online: 5 April 2017

(C) The Author(s) 2017. This article is published with open access at Springerlink.com

\begin{abstract}
Algal-induced turbidity has been shown to alter several important aspects of reproduction and sexual selection. However, while turbidity has been shown to negatively affect reproduction and sexually selected traits in some species, it may instead enhance reproductive success in others, implying that the impact of eutrophication is far more complex than originally believed. In this study, we aimed to provide more insight into these inconsistent findings. We used molecular tools to investigate the impact of algal turbidity on reproductive success and sexual selection on males in controlled laboratory experiments, allowing mate choice, mating competition, and mate encounter rates to affect reproduction. As study species, we used the broad-nosed pipefish, Syngnathus typhle, a species practicing male pregnancy and where we have previously shown that male mate choice is impaired by turbidity. Here, turbidity instead enhanced sexual selection on male size
\end{abstract}

Communicated by J. Frommen

Electronic supplementary material The online version of this article (doi:10.1007/s00265-017-2310-8) contains supplementary material, which is available to authorized users.

Josefin Sundin

josefin.sundin@neuro.uu.se; josefin@teamsundin.se

1 Department of Ecology and Genetics/Animal Ecology, Uppsala University, Uppsala, Sweden

2 Present address: Department of Neuroscience, Uppsala University, Uppsala, Sweden

3 Centre for Biodiversity Dynamics, Department of Biology, Norwegian University of Science and Technology,

Trondheim, Norway

4 Norwegian Institute for Nature Research (NINA), Trondheim, Norway and mating success as well as reproductive success. Effects from mating competition and mate encounter rates may thus override effects from mate choice based on visual cues, producing an overall stronger sexual selection in turbid waters. Hence, seemingly inconsistent effects of turbidity on sexual selection may depend on which mechanisms of sexual selection that have been under study.

\section{Significance statement}

Algal blooms are becoming increasingly more common due to eutrophication of freshwater and marine environments. The high density of algae lowers water transparency and reduces the possibility for fish and other aquatic animals to perform behaviors dependent on vision. We have previously shown that pipefish are unable to select the best partner in mate choice trials when water transparency was reduced. However, fish might use other senses than vision to compensate for the reduction in water transparency. In this study, we found that when fish were allowed to freely interact, thereby allowing competition between partners and direct contact between the fish, the best partner was indeed chosen. Hence, the negative effects of reduced water visibility due to algal blooms may be counteracted by the use of other senses in fish.

Keywords Climate change - Eutrophication - Syngnathidae Baltic Sea $\cdot$ Sex-role reversal

\section{Introduction}

Human-induced changes, such as climate change (Bradshaw and Holzapfel 2006), pollution (Carson 1962; Lurling and Scheffer 2007), selective harvesting (Law 2000; Coltman et al. 2003), urbanization (Marzluff et al. 2008), deforestation, and habitat fragmentation (Saunders et al. 1991; Skole and 
Tucker 1993), affect the abundance, distribution, and evolution of organisms. An organism's resilience to such fast and drastic environmental change largely depends on its ability to disperse, its mobility, its behavioral plasticity, and the fitness consequences related to the environmental change (Dall et al. 2005; Donaldson-Matasci et al. 2008). The severity and speed of changes induced by humans imply that organisms need to adapt to the new environment at a very short time scale in order to persist (Tuomainen and Candolin 2010; Sih 2013; Wong and Candolin 2015).

Coastal ecosystems are particularly sensitive to humaninduced environmental change such as eutrophication, which can lead to an extreme growth of phytoplankton and filamentous algae (Smith 2003). Algal-induced turbidity decreases water transparency, narrows the light spectrum (Jerlov 1976; Seehausen and van Alphen 1998), and changes chemical properties of the water (Lapointe and Matzie 1996; Perus and Bonsdorff 2004). Species vary greatly in how they respond to turbidity. For example, turbidity and increased algal cover may hamper species-specific sexual signaling, leading to hybridization in Lake Victoria cichlids (Seehausen et al. 1997; Selz et al. 2014). It can relax sexual selection on male nuptial coloration and courtship activity, diminishing honest signaling of mate quality and increasing the probability of reproduction for parasitized males, as shown in the three-spined stickleback (Candolin et al. 2007; Wong et al. 2007; Heuschele and Candolin 2010). Turbidity can further relax sexual selection on mate size and decrease parental care in the sand goby (Järvenpää and Lindström 2004, 2011), increase latency until courting in the desert goby (Michelangeli et al. 2015), and decrease mate search and evaluation in the sailfin molly and in the three-spined stickleback (Heubel and Schlupp 2006; Heuschele et al. 2012). All these studies thus show adverse effects of turbidity in traits and behaviors relevant for population viability. By contrast, turbidity and increased algal cover have been shown to enhance reproductive success through increased reproductive lifespan and increased hatching success in the three-spined stickleback (Candolin et al. 2008, 2014) and increased egg survival in the sand goby (Järvenpää and Lindström 2011). These conflicting results imply that the impact of eutrophication is far more complex than originally believed, in particular when studied under more natural conditions. The object of this study is therefore to increase our understanding on the effects of turbidity on sexual selection under more natural conditions by exploring additional mechanisms of sexual selection, such as mating competition and mate encounter rates.

We experimentally investigated the impact of algal turbidity on mating probability (proportion of mated males), mating success (number of partners), and reproductive success (number of eggs), using the broad-nosed pipefish, Syngnathus typhle. Turbidity may have particularly severe consequences for $S$. typhle since this species relies on visual cues in mate choice (Rosenqvist and Berglund 2011). Furthermore, this pipefish is probably not able to completely compensate for a reduction in visibility by switching to other sensory systems since chemoreception (Sundin et al. 2010; Lindqvist et al. 2011) as well as sound (Ripley and Foran 2007, investigated for S. floridae and S. fuscus) seem less important in mate search or mate choice for this fish. However, chemoreception should not be completely ruled out due to the use of MHC during mate choice in this species (Roth et al. 2014). Both males and females are choosy, with body size being an important mate choice cue (Berglund et al. 1986b; Sandvik et al. 2000). Fecundity increases with size (Berglund et al. 1986a, b; Sandvik et al. 2000), which is true for many other species across a broad range of taxa, and mating preference for large body size is thus very common (Andersson 1994). We have previously shown that sexual selection on mate size through mate choice of visual cues is impaired in turbid waters (Sundin et al. 2010). We now set out to explore how additional mechanisms of sexual selection, such as mating competition and mate encounter rates, affect sexual selection on mate size in turbid waters. We did this by allowing males and females to interact freely in controlled mating experiments in clear or turbid water. We subsequently assessed the genetic mating system using microsatellite markers. We used fish from the Baltic Sea population which has experienced high levels of turbidity (Bonsdorff et al. 2002; Salonen et al. 2009; Veneranta et al. 2011) and may thus be adapted to these conditions. This is suggested by its overall robustness to hypoxic conditions (which may be caused by algal blooms) during a mating event (Sundin et al. 2015) and the lack of a turbidity effect on the development of sexual ornaments in the closely related straight-nosed pipefish, Nerophis ophidion (Sundin et al. 2016).

Given the findings in the majority of previous studies on effects of turbidity on sexual selection cited above, we still hypothesized that turbidity would relax sexual selection on mate size and decrease mating as well as reproductive success.

\section{Methods}

\section{Catching and handling}

We collected pipefish in the Baltic Sea, at Kyllaj on the east coast of Gotland, Sweden $\left(57^{\circ} 44^{\prime} \mathrm{N}, \mathrm{E} 18^{\circ} 57^{\prime} \mathrm{E}\right)$ in May 2010. We trawled shallow ( $<10 \mathrm{~m}$ deep) meadows of eelgrass, Zostera marina, using a beam trawl (mesh size $4 \mathrm{~mm}$ ) pulled by a motorboat. In the laboratory at Ar research station, we kept the pipefish separated by sex in 650-1 holding tanks (12 tanks in total) with continuously renewed seawater and artificial eelgrass for shelter. Temperature and salinity followed local conditions during the holding period (holding period May-June: temperature $8-20{ }^{\circ} \mathrm{C}$, salinity $6.0-6.5 \%$ ) . 
The light cycle was set to $\mathrm{L} 17 \mathrm{~h} / \mathrm{D} 7 \mathrm{~h}$. We fed the fish three times a day with live and frozen mysid shrimps and laboratory raised Artemia sp. Tanks were cleaned daily. The same feeding regime was also applied during the experiment.

\section{Experimental design}

The experiment investigating the impact of algal turbidity on mating probability (proportion of mated males), mating success (number of partners), and reproductive success (number of eggs) ran from June 23 to 30, 2010. We allowed four females and four males to freely interact and breed in either clear or turbid water ( 16 replicates per treatment) during 4 days (which is ample time for the fish to mate; Berglund et al. 1989; Jones et al. 2005). Prior to the experiment, we measured standard length of all fish, and for females, we also measured body depth. Fish length and depth overlapped between treatments (mean $\pm \mathrm{SD}, N=64$ fish per sex and treatment (apart from female turbid where $N=63$, since one female turned out to be a male), length: females: clear $135.1 \pm 13.7 \mathrm{~mm}$, turbid $137.5 \pm 12.7 \mathrm{~mm}$, males: clear $132.1 \pm 9.6 \mathrm{~mm}$, turbid $133.5 \pm 10.9 \mathrm{~mm}$; female depth: clear $6.5 \pm 1.1 \mathrm{~mm}$, turbid $6.6 \pm 1.1 \mathrm{~mm}$ ). We also looked for skin parasites (Cryptocotyle sp.) as parasites can make mates unattractive (Rosenqvist and Johansson 1995). If larger fish had more parasites than smaller fish, this could have induced complications for measurements of sexual selection on mate size. No fish included in the final analyses had more than four visible Cryptocotyle sp., and there was no correlation between fish size and number of parasites (linear regression: $r^{2}=0.03, F_{1,96}=2.52, P=0.116$,). For breeding tanks, we used 650-1 tanks $(1 \times 1 \times 1 \mathrm{~m}$, water depth $0.65 \mathrm{~m})$, thus generating a density of 0.01 fish per liter water $(8$ fish in $650 \mathrm{l}$ ), which allows sexual selection to operate (Aronsen et al. 2013a, b). The tanks were equipped with artificial eelgrass for shelter and air stones for oxygen supply. For the turbid treatment, we manipulated algal turbidity by adding frozen Nannochloropsis sp. algae (Instant Algae Nanno $3600 \AA$, Microalgae), mixed with seawater prior the start of the experiment, to reach the targeted turbidity level of 10 nephelometric turbidity units (NTU). This corresponds to high, but not extreme, turbidity levels in the Baltic Sea (Salonen et al. 2009; Veneranta et al. 2011). The aeration of the water prevented algae from sinking to the bottom and kept the turbidity level relatively constant. Turbidity and temperature were measured two to three times per day using a HANNAH HI93703 turbidity meter. There were no differences in temperature between treatments (mean $\pm \mathrm{SD}, 136$ measurements per treatment: clear $16.7 \pm 1.9{ }^{\circ} \mathrm{C}$, turbid $16.8 \pm 2.0{ }^{\circ} \mathrm{C}$ ). Mean turbidity levels between replicates in the turbid treatment (144 measurements in total) varied from 9.43 to 10.69 NTU, overall turbidity varied between 8.16 and 13.16 NTU (mean $10.07 \pm 0.9)$. Turbidity levels of clear water were below the threshold level of the turbidity meter $(0.5 \mathrm{NTU})$.
On day 4 (the last day of each set of replicates), we finclipped the females by cutting approximately $3 \mathrm{~mm}^{2}$ of tissue from the caudal fin, after which females were released back into the wild at approximately the site of capture, along with non-pregnant males. Pregnant males were transferred to 21-1 flow-through brooding aquaria equipped with artificial eelgrass for shelter, each replicate separate. We kept the males until the embryos had developed eyespots to enable parentage analysis of the embryos (Jones et al. 1999). We then euthanized the males by giving them an overdose of the sedative 2phenoxyethanol $(2 \mathrm{ml} / \mathrm{l})$, after which we severed their spinal column above the operculum. Males were then stored in $95 \%$ ethanol, with embryos kept in the pouch of the males. It was not possible to record data blind due to the turbidity treatment, which is visible to any observer.

\section{Parentage analysis}

To investigate the impact of algal turbidity on mating success and reproductive success, we assessed parentage using three highly polymorphic microsatellite loci (Typh04, Typh16, and Typh18), developed by Jones et al. (1999). All eggs were dissected from the membrane of the father's brood pouch using flame-sterilized forceps, mapping their position within the brood pouch as they were extracted. Also, dead/unfertilized eggs were dissected and their position noted. Since eggs are spatially clumped by maternity in the male brood pouch, genotyping every fourth embryo gives enough resolution to assign the eggs to each mother (Jones and Avise 1997; Jones et al. 1999). The methods for DNA extraction, amplification of microsatellite loci, and scoring of fragment sizes are described in Aronsen et al. (2013a).

Mothers were assigned to each offspring using Cervus 3.0 (Kalinowski et al. 2007). Cervus assigned 99\% of the offspring to a candidate mother with $95 \%$ confidence. The remaining $1 \%$ was assigned to a mother manually by using the information from the genotyped embryos located before and after the unassigned embryo. When the assigned embryos before and after the unassigned embryo belonged to different mothers, we assigned half of the embryos in-between (i.e., two embryos, as every fourth embryo was genotyped) to each of the mothers.

\section{Males affected by mold}

During the pregnancy, males are very sensitive to all forms of infections (Landis et al. 2012; Sagebakken et al. 2016). Unfortunately, during the brooding period, many males got an infection most likely caused by Saprolegnia. Water molds (oomycetes) of the genus Saprolegnia cause Saprolegniosis, which is a disease that is characterized by visible white or gray patches of filamentous mycelium on the body or fins of fishes (van West 2006). Out of the 49 mated males, 26 were infected 
in the turbid treatment, and 11 out of 49 in the clear water treatment, meaning that more males were infected in the turbid than the clear treatment (GLM (using binomial response variable, $1=$ infected, $0=$ not infected): $z$-value $=2.86, P=0.004$, intercept (clear treatment): estimate $\pm \mathrm{SE}$ (logit scale) $=-1.57 \pm 0.33$, treatment (turbid): estimate \pm SE (logit scale) $=1.19 \pm 0.42$, estimate for the turbid treatment is given as the contrast to the intercept (clear treatment)). The embryos carried by the infected fish could not be included in the parentage analyses. However, in neither the turbid nor the clear treatment did the males with and without the mold infection differ significantly in length (turbid: mean \pm SD: infected $137.0 \pm 8.64 \mathrm{~mm}$, uninfected $135.9 \pm 8.40 \mathrm{~mm}$, Wilcoxon signed-rank: $W=0.365, P=0.08$, clear: mean $\pm \mathrm{SD}$ : infected $127.5 \pm 10.24 \mathrm{~mm}$, uninfected $133.5 \pm 8.68 \mathrm{~mm}$, Wilcoxon signed rank: $W=380, P=0.12)$. Hence, while the unfortunate mold infection caused a decrease in sample size, it did not cause a skew in size of the fish available for parentage analyses and should thus not influence the measures of sexual selection.

\section{Statistical analysis}

To investigate whether algal turbidity had an impact on mate choice and mating success, we tested if there was any effect of treatment on proportion of mated fish and on mating (number of partners) or reproductive (number of eggs) success. For the models of proportion of mated fish, mating success, and reproductive success, we included replicate as a random effect (since fish within a replicate are not independent from each other), while treatment was the fixed factor (with two levels: clear and turbid). Length was included as a covariate. We used the method of Zuur et al. (2009) for model selection. We removed non-significant interactions $(P>0.1)$ from the final model using log likelihood tests (LRT) based on maximum likelihood. Only the minimum adequate models are presented (Table 1).

For the analysis of proportion of mated fish, we used a generalized linear mixed effect model (GLMM), with binominal error structure and logit-link function. Mated or not mated was the response variable $(n=64$ males per treatment).

For the analysis of mating success (data gained from the parentage analysis), we used a GLMM with a poisson error distribution and log-link function. Number of partners (0-4) was the response variable ( $n=$ clear 53 males (16 replicates), turbid 38 males (16 replicates), i.e., including all mated males that were not infected and males that had not mated ( 0 partners) from all 16 replicates per treatment). Remaining males could not be included since the parentage analysis could not be conducted as the males had undeveloped eggs or had gotten a mold infection during the pregnancy.

The analysis of reproductive success (data gained from the parentage analysis) was equivalent to the analysis of mating success, with the exception that an individual level random effect was added to the model to account for overdispersion. The number of developed embryos was the response variable for males (since we genotyped every fourth embryo, we calculated reproductive success as four times the number of embryos that showed signs of embryo-development and hence could be genotyped). Males excluded in the prior analysis were again excluded for the same reasons.

Females were not analyzed due to the infection in many males (i.e., rendering data on female mating and reproductive success unreliable as we cannot know, with any certainty, which females that contributed eggs to the infected males), as described above. All analyses were performed using $\mathrm{R}$ version 2.13.1 (R Development Core Team 2011), with the Ime4 package (Bates et al. 2011).
Table 1 The effect of treatment (clear and turbid) and length $(\mathrm{mm})$ on male mating probability (proportion of mated males), mating success (number of partners), and reproductive success (number of eggs)

\begin{tabular}{llrrr}
\hline Response & & Estimate $( \pm$ SE) & \multicolumn{1}{c}{ z } & $P$ \\
\hline Mating probability & Intercept (clear) & $0.73(4.07)$ & 0.18 & 0.858 \\
& Treatment (turbid) & $-17.17(6.61)$ & -2.60 & 0.009 \\
& Length & $0.003(0.03)$ & 0.11 & 0.911 \\
& Treatment (turbid)*length & $0.13(0.05)$ & 2.59 & 0.010 \\
Mating success & Intercept (clear) & $-1.11(1.71)$ & -0.65 & 0.514 \\
& Treatment (turbid) & $-6.41(2.89)$ & -2.22 & 0.027 \\
& Length & $0.01(0.01)$ & 0.87 & 0.385 \\
Reproductive success & Treatment (turbid)*length & $0.04(0.02)$ & 2.12 & 0.034 \\
& Intercept (clear) & $0.04(5.08)$ & -0.03 & 0.978 \\
& Treatment (turbid) & $-18.36(7.53)$ & -2.44 & 0.015 \\
& Length & $0.02(0.04)$ & 0.43 & 0.671 \\
& Treatment (turbid)*length & $0.13(0.06)$ & 2.35 & 0.019 \\
\hline
\end{tabular}

All tests are GLMMs with replicate as a random factor. Estimates are reported as contrasts to the intercept 


\section{Results}

\section{Mating probability}

Out of the 64 males, 49 mated in the turbid as well as in the clear treatment. The interaction between male body length and turbidity was significant (Fig. 1, Table 1), and when the relationship between mating probability and male body length was tested separately for the two treatments, there was a significant positive relationship between male length and mating probability in the turbid treatment (GLMM: estimated slope $\pm \mathrm{SE}($ logit scale $)=0.16 \pm 0.06, \mathrm{z}$-value $=2.84$, $P=0.005$ ). In contrast, there was no relationship between male length and the mating probability in the clear treatment $($ GLMM: estimated slope $\pm \mathrm{SE}$ (logit scale $)=0.003 \pm 0.03, \mathrm{z}-$ value $=0.11, P=0.91)($ Fig. 1 , Table 1$)$.

\section{Mating success}

Larger males mated with more females, and the relationship between male body length and number of partners was stronger in turbid environments (Fig. 2a, Table 1). The difference in the relationship between male length and number of partners in the turbid and clear treatments was due to small males having more partners in the clear treatment than in the turbid treatment. The median male length was $143 \mathrm{~mm}$; we therefore tested for differences in mating success between treatments for males less than $143 \mathrm{~mm}$ (small males) or males that were $143 \mathrm{~mm}$ or longer (large males). Males less than $143 \mathrm{~mm}$ in length had significantly more mates in the clear than in the turbid treatment (Wilcoxon rank sum test: $W=863.5$, $P=0.04)$. There were, however, no differences in the number of partners between males from the turbid and clear treatment when only considering males that were $143 \mathrm{~mm}$ or longer (Wilcoxon rank sum test: $W=23.5, P=0.71$ ).

\section{Reproductive success}

Reproductive success followed the same pattern as mating probability and mating success, with a significant interaction between length and treatment, showing that the positive relationship between male body length and number of eggs received was stronger in the turbid treatment (Fig. 2b, Table 1).

\section{Discussion}

The available studies on the effects of turbidity on sexual selection show very mixed results, sometimes demonstrating an increase, sometimes a decrease, and sometimes no effect on sexual selection (Järvenpää and Lindström 2004, 2011; Candolin et al. 2007, 2014; Wong et al. 2007; Heuschele and Candolin 2010). Here, we provide more insight into these inconsistencies: in a previous experiment, when we allowed mate choice on visual and/or chemosensory cues to influence the outcome, turbidity had negative effects on sexual selection and the addition of chemosensory cues could not counteract the reduction in visibility (Sundin et al. 2010). When allowing full-contact between the sexes, i.e., mating competition and mate encounter rates in addition to visual cues, as in this study, mimicking more natural conditions, things changed dramatically: turbidity actually increased sexual selection on body size in males. Most likely, the effects from mating competition and/or altered mate encounter rates under turbidity overrode possible effects from a hampered mate choice, producing a net increase in sexual selection on male length. The increased selection on male length was due to a reduction in mating and reproductive success in small males (Fig. 2a, b). This may be due to two reasons: small males did worse in mating competition under turbidity or they suffered a decrease in mate encounter rates. The former seems less likely, as male-male competition is not overwhelmingly strong in this sex-role reversed species (Berglund and Rosenqvist 2003). The possibility that small individuals are less frequently encountered or not correctly identified as potential mates under turbid conditions may, however, be more likely: random encounters should be more frequent with larger individuals, or larger individuals are more easily identified as potential partners than are small individuals under low visibility regimes. Turbidity in itself does not seem to have an effect on overall swimming
Fig. 1 Estimated relationships from GLMM between mating probability (logit scale) and male length in the clear (blue line) and turbid (green line) treatment. Thin lines indicate $95 \%$ confidence intervals and have the same line color (blue and green) as the treatment they belong to. Estimates of the probability of mating are from the model presented in Table 1

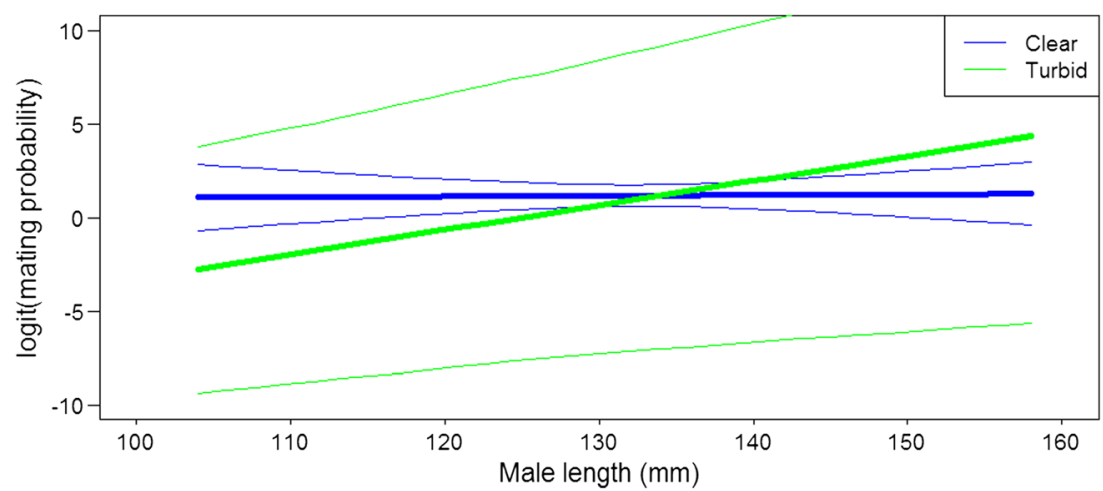


Fig. 2 Estimated relationships (logarithmic scale) from GLMMs between the number of partners (a) and number of offspring (b) and male length in the clear (blue line) and turbid (green line) treatment. Thin lines indicate $95 \%$ confidence intervals and have the same line color (blue and green) as the treatment they correspond to. The estimated relationships are from the models presented in Table 1
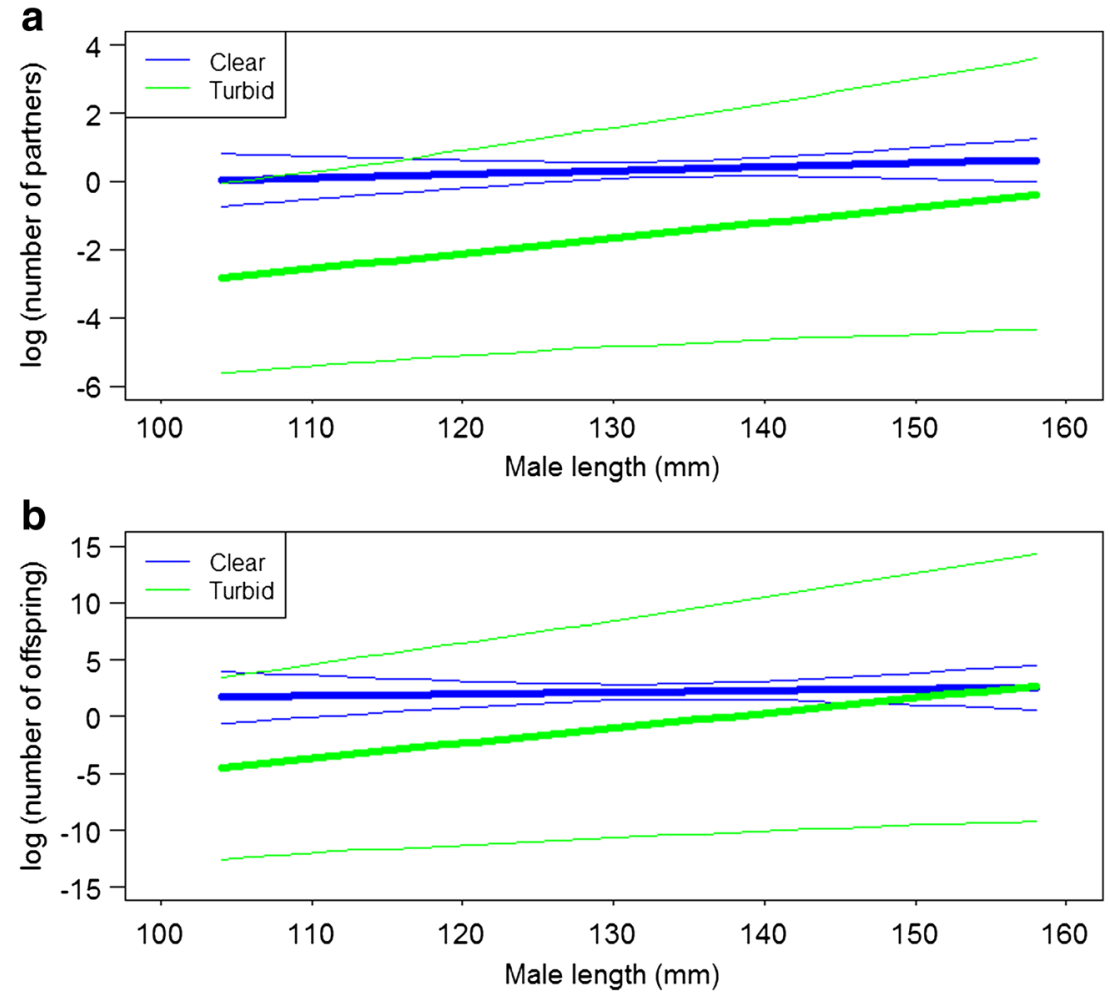

activity, as shown in S. typhle (Sundin et al. 2010) as well as in the closely related straight-nosed pipefish, Nerophis ophidion (Sundin et al. 2016). Unfortunately, we could not assess sexual selection in females due to the mold outbreak.

The mold outbreak affected many pregnant males when we reared them for maternity analysis, and the males from the turbidity treatment were worse infected than males from the clear treatment. The infected males could still be used for assessing mating probability, but not for assessing mating or reproductive success. In the latter two analyses, we consequently overestimate the proportion of unmated males by including replicates with many infected males, as only mated males were affected. Since males from the turbidity treatment were worse affected than the clear water treatment, this could have skewed our results, but pregnant males from the turbid treatment without the infection did not differ from pregnant males with the infection in body size. Hence, the size-specific results that we found here were most likely not confounded by the mold infection, since the infection was size indiscriminate. Hence, we believe that the result that sexual selection acted stronger in turbid water by decreasing mating and reproductive success in small males still holds. The fact that the males from the turbid treatment were infected to a greater extent than males from the clear treatment is still an interesting finding in itself, and it suggests that those males for unknown reasons were more susceptible to the mold infection. This study was not designed to investigate the possible effects of turbidity on infection susceptibility, and to our knowledge, this has not been explicitly tested in fish. Sirois and Dodson (2000) found that larval rainbow smelt (Osmerus mordax) from a collection site with high turbidity (50 NTU) had a higher prevalence of cestode parasites compared to fish collected from a site with lower turbidity (20 NTU). Although there were additional differences between the two collection sites, their finding follows our observation that high turbidity may lead to higher susceptibility for infection, and it offers an interesting venue for further research.

Both the probability of a male to have mated, as well as mating success, was random with respect to size in clear water. This suggests that mate size was not the predominant mate choice cue used by females in this more natural experimental setup where additional cues could be used, and where interaction between the sexes was permitted. This result is in accordance to what has been found for male mate choice in this Baltic Sea population (Sundin et al. 2013). It is, however, in contrast to the population on the Swedish west coast, where females as well as males have been shown to prefer larger mates (Berglund et al. 1986a, b; but see Mobley et al. 2013), and fecundity and body size are closely correlated (Berglund et al. 1986a). The difference in the relationship between male length and number of partners in the turbid and clear treatments found here was due to small males having more partners in the clear than in the turbid treatment, again showing that mate size is not important in mate choice in clear water. Previous research has 
shown that turbidity relaxes sexual selection on mate size (Järvenpää and Lindström 2004; Sundin et al. 2010; Sundin et al. 2016). Since mating with a larger mate may come with fitness benefits to the offspring in this species (Berglund et al. 1986a; Ahnesjö 1992; Mazzi 2004), turbidity may lead to an enhanced reproductive success.

\section{Conclusion}

When mechanisms of sexual selection were limited to mate choice based on visual cues, turbidity hampered sexual selection (Sundin et al. 2010). We have shown that when additional mechanisms, such as mating competition and mate encounter rates, were allowed to influence sexual selection, turbidity could actually increase sexual selection in a population severely affected by turbidity in nature. Given the increase in human disturbance on ecosystems, studying the impact of environmental stressors is not only important to better understand how environmental fluctuations affect evolutionary processes, but also for conservation biology and studies of the resilience of organisms to anthropogenic induced environmental change.

Acknowledgments Financial support was provided by Zoologiska stiftelsen, Inez Johanssons stiftelse, and The Royal Swedish Academy of Sciences (JS), the Nordic Marine Academy (TA), the Norwegian Research Council (186163/V40), the Association of European Marine Biological Laboratories, and partly supported by the Research Council of Norway through its Centers of Excellence funding scheme (22325) (GR), and the Swedish Research Council (AB). We thank R. Höglund, C. Lindqvist, and Ö. Jacobsson for field assistance and F. Jutfelt for advice on turbidity manipulation. The Ar Research Station provided excellent working facilities. Thanks to A. Robertsson and R. Dufva for laboratory assistance and to K. Mobley for advice on the parentage analysis. Thanks to Joachim Frommen and two anonymous reviewers for valuable comments on the manuscript.

Author's contributions JS, TA, GR, and AB designed and performed the experiment. TA and JS analyzed the data. JS wrote the manuscript draft with significant contribution of TA, GR, and AB.

\section{Compliance with ethical standards}

Ethical approval The experiment was performed according to current national legislation on Animal Welfare under license Dnr S 155-09 from the Swedish Board of Agriculture. The research facilities at Ar research station are approved to house and to use research animals (Dnr A10 2012/ 215 from the Swedish Board of Agriculture, and Dnr C10-2006/570 from the former Swedish animal welfare agency).

Open Access This article is distributed under the terms of the Creative Commons Attribution 4.0 International License (http:// creativecommons.org/licenses/by/4.0/), which permits unrestricted use, distribution, and reproduction in any medium, provided you give appropriate credit to the original author(s) and the source, provide a link to the Creative Commons license, and indicate if changes were made.

\section{References}

Ahnesjö I (1992) Consequences of male brood care: weight and number of newborn in a sex-role reversed pipefish. Funct Ecol 6:274-281

Andersson M (1994) Sexual selection. Princeton University Press, Princeton

Aronsen T, Berglund A, Mobley BM, Ratikainen II, Rosenqvist G (2013a) Sex ratio and density affect sexual selection in a sex-role reversed fish. Evolution 67:3243-3257

Aronsen T, Mobley KB, Berglund A, Sundin J, Billing AM, Rosenqvist $G$ (2013b) The operational sex ratio and density influence spatial relationships between breeding pipefish. Behav Ecol 24:888-897

Bates D, Mächler M, Bolker B (2011) lme4: linear mixed-effects models using s4 classes. R package version 0.999375-42, http://CRAN.Rproject.org/package=lme4

Berglund A, Rosenqvist G (2003) Sex role reversal in pipefish. Adv Stud Behav 32:131-167

Berglund A, Rosenqvist G, Svensson I (1986a) Mate choice, fecundity and sexual dimorphism in 2 pipefish species (Syngnathidae). Behav Ecol Sociobiol 19:301-307

Berglund A, Rosenqvist G, Svensson I (1986b) Reversed sex-roles and parental energy investment in zygotes of 2 pipefish (Syngnathidae) species. Mar Ecol-Prog Ser 29:209-215

Berglund A, Rosenqvist G, Svensson I (1988) Multiple matings and parental brood care in the pipefish Syngnathus typhle. Oikos 51: 184-188

Berglund A, Rosenqvist G, Svensson I (1989) Reproductive success of females limited by males in 2 pipefish species. Am Nat 133:506516

Bonsdorff E, Rönnberg C, Aarnio K (2002) Some ecological properties in relation to eutrophication in the Baltic Sea. Hydrobiologia 475:371377

Bradshaw WE, Holzapfel CM (2006) Climate change - evolutionary response to rapid climate change. Science 312:1477-1478

Candolin U, Salesto T, Evers M (2007) Changed environmental conditions weaken sexual selection in sticklebacks. J Evol Biol 20:233239

Candolin U, Engström-Öst J, Salesto T (2008) Human-induced eutrophication enhances reproductive success through effects on parenting ability in sticklebacks. Oikos 117:459-465

Candolin U, Nieminen A, Nyman J (2014) Indirect effects of humaninduced environmental change on offspring production mediated by behavioural responses. Oecologia 174:87-97

Carson R (1962) Silent Spring. Houghton Mifflin, New York

Coltman DW, O'Donoghue P, Jorgenson JT, Hogg JT, Strobeck C, FestaBianchet M (2003) Undesirable evolutionary consequences of trophy hunting. Nature 426:655-658

Dall SRX, Giraldeau LA, Olsson O, McNamara JM, Stephens DW (2005) Information and its use by animals in evolutionary ecology. Trends Ecol Evol 20:187-193

Donaldson-Matasci MC, Lachmann M, Bergström CT (2008) Phenotypic diversity as an adaptation to environmental uncertainty. Evol Ecol Res 10:493-515

Heubel KU, Schlupp I (2006) Turbidity affects association behaviour in male Poecilia latipinna. J Fish Biol 68:555-568

Heuschele J, Candolin U (2010) Reversed parasite-mediated selection in sticklebacks from eutrophied habitats. Behav Ecol Sociobiol 64: 1229-1237

Heuschele J, Salminen T, Candolin U (2012) Habitat change influences mate search behaviour in three-spined sticklebacks. Anim Behav 83: $1505-1510$

Järvenpää M, Lindström K (2004) Water turbidity by algal blooms causes mating system breakdown in a shallow-water fish, the sand goby Pomatoschistus minutus. Proc R Soc Lond B 271:2361-2365 
Järvenpää M, Lindström K (2011) Algal blooms decrease care but increase egg survival in a fish with paternal care. Behav Ecol Sociobiol 65:2023-2028

Jerlov NG (1976) Marine optics. Elsevier, Amsterdam

Jones AG, Avise JC (1997) Microsatellite analysis of maternity and the mating system in the Gulf pipefish Syngnathus scovelli, a species with male pregnancy and sex-role reversal. Mol Ecol 6:203-213

Jones AG, Rosenqvist G, Berglund A, Avise JC (1999) The genetic mating system of a sex-role-reversed pipefish (Syngnathus typhle): a molecular inquiry. Behav Ecol Sociobiol 46:357-365

Jones AG, Rosenqvist G, Berglund A, Avise JC (2005) The measurement of sexual selection using Bateman's principles: an experimental test in the sex-role-reversed pipefish Syngnathus typhle. Integr Comp Biol 45:874-884

Kalinowski ST, Taper ML, Marshall TC (2007) Revising how the computer program CERVUS accommodates genotyping error increases success in paternity assignment. Mol Ecol 16:1099-1106

Landis SH, Sundin J, Rosenqvist G, Roth O (2012) Behavioral adjustments of a pipefish to bacterial Vibrio challenge. Behav Ecol Sociobiol 66:1399-1405

Lapointe BE, Matzie WR (1996) Effects of stormwater nutrient discharges on eutrophication processes in nearshore waters of the Florida keys. Estuaries 19:422-435

Law R (2000) Fishing, selection, and phenotypic evolution. ICES J Mar Sci 57:659-668

Lindqvist C, Sundin J, Berglund A, Rosenqvist G (2011) Male broadnosed pipefish Syngnathus typhle do not locate females by smell. J Fish Biol 78:1861-1867

Lurling M, Scheffer M (2007) Info-disruption: pollution and the transfer of chemical information between organisms. Trends Ecol Evol 22: 374-379

Marzluff JM, Shulenberger E, Endlicher W, Alberti M, Bradley G, Ryan C, Simon U, ZumBrunnen C (eds) (2008) Urban ecology: an international perspective on the interaction between humans and nature. Springer Science, New York

Mazzi D (2004) Parasites make male pipefish careless. J Evol Biol 17: 519-527

Michelangeli M, Tuomainen T, Candolin U, Wong BBM (2015) Habitat alteration influences male signalling effort in the Australian desert goby. Behav Ecol 26:1164-1169

Mobley KB, Chakra MA, Jones AG (2013) No evidence for sizeassortative mating in the wild despite mutual mate choice in exrole reversed pipefishes. Ecol Evol 4:67-78

Perus J, Bonsdorff E (2004) Long-term changes in macrozoobenthos in the Alland archipelago, northern Baltic Sea. J Sea Res 52:45-56

R Development Core Team (2011) R: a language and environment for statistical computing. R Foundation for Statistical Computing, Vienna https://www.R-project.org/

Ripley JL, Foran CM (2007) Influence of estuarine hypoxia on feeding and sound production by two sympatric pipefish species (Syngnathidae). Mar Environ Res 63:350-367

Rosenqvist G, Berglund A (2011) Sexual signals and mating patterns in Syngnathidae. J Fish Biol 78:1647-1661

Rosenqvist G, Johansson K (1995) Male avoidance of parasitized females explained by direct benefits in a pipefish. Anim Behav 49:1039 1045

Roth O, Sundin J, Berglund A, Rosenqvist G, Wegner M (2014) Male mate choice relies on major histocompatibility complex class I in a sex-role reversed pipefish. J Evol Biol 27:929-938
Sagebakken G, Ahnesjö I, Kvarnemo C (2016) Costs and benefits to pregnant male pipefish caring for broods of different sizes. PLoS One 11:e 0156484

Salonen M, Urho L, Engström-Öst J (2009) Effects of turbidity and zooplankton availability on the condition and prey selection of pike larvae. Boreal Env Res 14:981-989

Sandvik M, Rosenqvist G, Berglund A (2000) Male and female mate choice affects offspring quality in a sex role reversed pipefish. Proc R Soc Lond B 267:2151-2155

Saunders DA, Hobbs RJ, Margules CR (1991) Biological consequences of ecosystem fragmentation - a review. Conserv Biol 5:18-32

Seehausen O, van Alphen JJM (1998) The effect of male coloration on female mate choice in closely related Lake Victoria cichlids (Haplochromis nyererei Complex). Behav Ecol Sociobiol 42:1-8

Seehausen O, van Alphen JJM, Witte F (1997) Cichlid fish diversity threatened by eutrophication that curbs sexual selection. Science 277:1808-1811

Selz OM, Pierotti ME, Maan ME, Schmid C, Seehausen O (2014) Female preference for male color is necessary and sufficient for assortative mating in 2 cichlid sister species. Behav Ecol 25:612-626

Sih A (2013) Understanding variation in behavioural responses to human-induced rapid environmental change: a conceptual overview. Anim Behav 85:1077-1088

Sirois P, Dodson JJ (2000) Influence of turbidity, food density and parasites on the ingestion and growth of larval rainbow smelt Osmerus mordax in an estuarine turbidity maximum. Mar Ecol-Prog Ser 193: $167-179$

Skole D, Tucker C (1993) Tropical deforestation and habitat fragmentation in the amzaon - satellite data from 1978 to 1988 . Science 260: $1905-1910$

Smith VH (2003) Eutrophication of freshwater and coastal marine ecosystems - a global problem. Environ Sci Pollut R 10:126-139

Sundin J, Berglund A, Rosenqvist G (2010) Turbidity hampers mate choice in a pipefish. Ethology 116:713-721

Sundin J, Rosenqvist G, Berglund A (2013) Altered oceanic pH impairs mating propensity in a pipefish. Ethology 119:86-93

Sundin J, Rosenqvist G, Berglund A (2015) Hypoxia delays mating in the broad-nosed pipefish. Mar Biol Res 11:747-754

Sundin J, Rosenqvist G, Myhren S, Berglund A (2016) Algal turbidity hampers ornament perception, but not expression, in a sex-role reversed pipefish. Ethology 122:215-225

Tuomainen U, Candolin U (2010) Behavioural responses to humaninduced environmental change. Biol Rev 86:640-657

Veneranta L, Urho L, Lappalainen A, Kallasvuo M (2011) Turbidity characterizes the reproduction areas of pikeperch (Sander lucioperca (L.)) in the northern Baltic Sea. Estuar Coast Shelf S 95:199-206

van West P (2006) Saprolegnia parasitica, an oomycete pathogen with a fishy appetite: new challenges for an old problem. Mycologist 20: 99-104

Wong BBM, Candolin U (2015) Behavioral responses to changing environments. Behav Ecol 26:665-673

Wong BBM, Candolin U, Lindström K (2007) Environmental deterioration compromises socially enforced signals of male quality in threespined sticklebacks. Am Nat 170:184-189

Zuur AF, Ieno EN, Walker N, Saveliev AA, Smith GM (2009) Mixed effects models and extensions in ecology with R. Springer, New York 